\title{
Are IL-31, IL-33, and PlGF candidate markers for Pre- eclampsia?
}

\author{
Basile F*, Santamaria A, Mannucci C, Calapai G, Saitta S, Baviera G, Gangemi S and D'Anna R \\ Department of Obstetrics and Gynecology, University of Messina, Via Consolare Valeria, Messina, Italy
}

\begin{abstract}
Pre-eclampsia is characterized by an intense inflammatory response, associated with endothelial dysfunction. Thus, pro-inflammatory molecules and cytokines may play a role in the pathogenesis of preeclampsia. This was a case-control study including 14 pre-eclamptic and 24 normotensive women. Our objective was to compare IL-31, IL-33, and Placental Growth Factor (PlGF) levels in the first and second trimester from patients with pre-eclampsia and normal pregnancies. While levels of IL-31, IL-33 did not change throughout normal pregnancy or pre-eclamptic women either in the first and in the second trimester, PIGF values in the second trimester were significantly lower in pre-eclamptic group compared to controls.
\end{abstract}

\section{Introduction}

Inflammation is a key feature of some obstetrical syndromes, which are associated with increased maternal and perinatal mortality and morbidity. Many cytokines are released from the intervillous space into the maternal circulation [1], and cause systemic maternal disease. This localized inflammation at the maternal-fetal interface has been observed in various pathological conditions, including Pre-eclampsia (PE) [2], spontaneous preterm birth [3], and unexplained fetal death $[4,5]$. The exact pathogenesis of PE remains unclear, but a central pathophysiologic feature of this syndrome is systemic inflammation, which secondarily involves extensive endothelial dysfunction in the maternal vascular system [6]. Insufficient extravillous trophoblast invasion of the uterus at the first trimester of gestation leads to placental hypoxia and subsequent impaired modification of the myometrial spiral arteries [7], and this determines placental dysfunction, resulting in an exaggerated endothelial activation and hyper-inflammatory state [2]. Thus, pro-inflammatory molecules and cytokines may play a role in the pathogenesis of PE. In agreement, several cytokines have been found to be elevated in women with PE and are of interest as possible markers for scoring the development of this disorder [1]. In this study, we evaluated in the first and second trimester the levels of two cytokines: IL-31 and IL-33 in pre-eclamptic women. IL-33, is a newly described member of the IL-1 family, and it has been demonstrated to induce cytokine synthesis, from immune cells, in particular IL-4, IL5 , and IL-13. IL-33 exert its inflammatory action through its receptor ST2 [8], expressed in the nuclei of endothelial cells of both large and small vessels, but also in the placental endothelium and smooth muscle cells [9]. In addition, we also evaluated Placental Growth Factor (PlGF) which is already considered an early marker of PE [10]. This study seeks to understand the pathogenesis of this devastating condition so that newer interventions and treatments can developed.

\section{Methods}

This is a case-control study, involving 37 pregnant women, selected among those included in the screening of Down syndrome. The study was carried out at the University Hospital of Messina, Italy, from January 2011 to October 2012. Written consent was obtained from pre-eclamptic and non-eclamptic women, before participation in the study. As matched controls $14 \mathrm{PE}$ and 23 normotensive pregnant women were included (Table 1). Of pre-eclamptic pregnancies, 5 patients were recruited in the first trimester (9-13 weeks gestation) and 9 in the second trimester (14-17 weeks). These women later went on develop PE. Pregnant women with pre-gestational diabetes mellitus and chronic hypertension were excluded from the study. Of the control, healthy women who had uncomplicated, at term pregnancies, 13 were recruited in the first trimester of pregnancy (9-13 weeks gestation), and 10 during the second (14-17 weeks; Table 1). Enzyme-Linked Immunosorbent Assay (ELISA) for human soluble free PlGF was performed on serum samples in duplicate using commercial kits $(\mathrm{R} \& \mathrm{D}$ Systems Inc., Minneapolis, MN, USA.). Levels of IL-31 and IL 33 were evaluated using a sandwich ELISA kit, according to the manufacturer's recommendations ( $\mathrm{R} \& \mathrm{D}$ Systems). The adsorbance was measured at $450 \mathrm{~nm}$, as this is the manufacturers recommendation. Data are expressed as means \pm SD for general characteristics and medians and interquartile range (IQR) for cytokine assays. Differences between data were analyzed by the Mann-Whitney U-test. Correlation between variables was evaluated with Spearman's rho. The statistical analysis was

Table 1. Clinical characteristics of preeclampsia and control women

\begin{tabular}{|l|l|l|l|}
\hline Charateristics & $\begin{array}{l}\text { Preecla1vipsia } \\
(\mathbf{n}=\mathbf{1 4})\end{array}$ & $\begin{array}{l}\text { Controls } \\
(\mathbf{n = 2 3 )}\end{array}$ & P value \\
\hline Maternal age (y) & $33 \pm 4.9$ & $34.3 \pm 3.9$ & n.s. \\
\hline Women weight $(\mathrm{Kg})$ & $69 \pm 12.2$ & $60.7 \pm 9.5$ & n.s. \\
\hline Nulliparity \% & 21.4 & 39.1 & n.s. \\
\hline GA at delivery (w) & $34.1 \pm 4$ & $38.4 \pm 2$ & $<0.05$ \\
\hline Birthweight (g) & $2116 \pm 95$ & $3211 \pm 458$ & $<0.05$ \\
\hline
\end{tabular}

Data are shown in mean $\pm \mathrm{SD}$, Abbrevations: Y: years; W: weeks; GA: Gestational Age g: grains

Correspondence to: Francesca Basile, Department of Obstetrics and Gynecology, University of Messina, Via Consolare Valeria, Messina, Italy, Tel: 393200923922; E-mail: francescab24@libero.it

Received: October 27, 2017; Accepted: December 0, 2017; Published: December 08,2017 
performed with SPSS for Windows (version 17.0). The level of statistical significance was always set at $P<0.05$.

\section{Results}

The characteristics of women included in the study are reported in Table 1. A significant difference in gestational age at delivery $(\mathrm{p}=0.003)$ and birth weight $(\mathrm{P}=0.002)$ between the two groups was observed ( $\mathrm{PE}$ vs controls). There were no significant differences in circulating levels of IL-31, IL-33 between the two groups, either in the first and in the second trimester. PlGF values in the second trimester were significantly lower in PE group compared to controls. Furthermore, no difference was observed, between the first and second trimester in IL-31 and IL33 concentrations (Table 2). In the PE group an inverse correlation was found between maternal age and either IL-33 $(\mathrm{p}=0.006)$ and PlGF $(\mathrm{p}=0.02)$ values. In the same group maternal weight was inversely correlated with IL-31 levels $(\mathrm{P}=0.03)$. In the control group, only at first trimester, an inverse correlation between IL-33 and birth weight was observed ( $\mathrm{p}=0.02)$, as well as, an inverse correlation between IL-31 and $\operatorname{PlGF}(\mathrm{p}=0.04)$.

\section{Discussion}

In this study, we could not demonstrate a role for IL-31 and IL-33 as early markers of PE, either in the first or in the second trimester, probably because of the small sample size. However, PlGF values of the second trimester, confirmed the importance of this marker as an early predictor of PE. PIGF is an angiogenic molecule member of the Vascular Endothelial Growth Factor (VEGF) family. In humans, serum levels of the PlGF have found reduced in women with PE [10,11]; thus, it has been proposed as a valide candidate for predicting PE [11]. The result of this study confirms a recent report, demonstrating that in pre-eclamptic women, at each trimester, no difference was detected in circulating IL-33 levels compared to a control group [12]. In the PE group we found an inverse correlation between IL-33 and PlGF, suggesting that very early cytokines are released while PlGF levels decrease. Another data that highlights the role of cytokines in fetal growth and development is the inverse correlation of IL-33 and fetal weight, suggesting that high cytokine levels may interfere with birth growth. Finally, the inverse correlation observed between IL-33 and maternal age, indicates that the cytokines-mediated systemic response is likely related to age. On the other hand, IL-31, is mainly produced by activated $\mathrm{T}$ helper cells. To date, this is the first report investigating maternal blood levels of IL-31 during pregnancy. IL-33 doesn't seem

Table 2. Serum levels of inflammatory mediators in preeclampsia and control women

\begin{tabular}{|c|c|c|c|}
\hline \multicolumn{4}{|c|}{ First Trimester } \\
\hline & $\begin{array}{l}\text { Cases } \\
(\mathbf{n}=\mathbf{5})\end{array}$ & $\begin{array}{l}\text { Controls } \\
(\mathrm{n}=13)\end{array}$ & $P$ value \\
\hline $\begin{array}{l}\text { IL-31 } \\
(\mathbf{n g} / \mathbf{m l})^{\text {a }}\end{array}$ & $593.5(101)$ & 489.4 (1967) & n.s. \\
\hline $\begin{array}{l}\text { IL-33 } \\
(\mathbf{n g} / \mathbf{m 1})^{\text {a }}\end{array}$ & $8.5(4)$ & $8.5(3)$ & n.s. \\
\hline PGIF $^{\text {a }}$ & $23.8(46)$ & $41.1(26)$ & n.s. \\
\hline \multicolumn{4}{|c|}{ Second Trimester } \\
\hline & $\begin{array}{l}\text { Cases } \\
(\mathrm{n}=9)\end{array}$ & $\begin{array}{l}\text { Controls } \\
(\mathrm{n}=10)\end{array}$ & \\
\hline $\begin{array}{l}\text { IL-31 } \\
(\mathbf{n g} / \mathbf{m l})^{a}\end{array}$ & 597 (4495) & $578.4(770)$ & n.s. \\
\hline $\begin{array}{l}\text { IL-33 } \\
\text { (ng/ml) a }\end{array}$ & $9.2(5)$ & $9.7(3)$ & n.s. \\
\hline PGIF $^{\text {a }}$ & $42.8(53)$ & $80.3(53)$ & $<0.05$ \\
\hline
\end{tabular}

"Differences between data series were analyzed by the Mann-Whitney test. involved in PE or placental damage and an inverse correlation with PlGF values was found in the control group. A definitive conclusion is hard to draw on the role of IL-31 and IL-33 as markers of PE, larger and further studies are needed to clarify the role of pro-inflammatory cytokines in normal and pathological pregnancies.

\section{References}

1. Benyo DF, Smarason A, Redman CW, Sims C, Conrad KP (2001) Expression of inflammatory cytokines in placentas from women with preeclampsia. J Clin Endocrinol Metab 86: 2505-2512. [Crossref]

2. Redman CW, Sacks GP, Sargent IL (1999) Preeclampsia: an excessive maternal inflammatory response to pregnancy. Am J Obstet Gynecol 180: 499-506. [Crossref]

3. Romero R, Espinoza J, Kusanovic JP, Gotsch F, Hassan S, et al. (2006) The preterm parturition syndrome. BJOG 3: 17-42. [Crossref]

4. Lee J, Romer R, Dong Z, Xu Y, Qureshi F, et al. (2011) Unexplained fetal death as a biological signature of maternal anti-fetal rejection: chronic chorioamnionitis and allo immune anti-human leucocyte antigen antibodies. Hystopathology 59: 928-38. [Crossref]

5. Walker JJ (2000) Pre-eclampsia. Lancet 356: 1260-1265. [Crossref]

6. Roberts JM, Gammill HS (2005) Preeclampsia: recent insights. Hypertension 46: $1243-$ 1249. [Crossref]

7. Meekins JW, Pijnenborg R, Hanssens M, McFadyen IR, van Asshe A (1994) A study of placental bed spiral arteries and trophoblast invasion in normal and severe preeclamptic pregnancies. Br J Obstet Gynaecol 101: 669-674. [Crossref]

8. Schmitz J, Owyang A, Oldham E, Song Y, Murphy E, et al. (2005) IL-33, an interleukin-1-like cytokine that signals via the IL-1 receptor-related protein ST2 and induces T helper type 2-associated cytokines. Immunity 23: 479-490. [Crossref]

9. Topping V, Romero R, Than NG, Tarca AL, Xu Z, et al. (2013) Interleukin-33 in the human placenta. J Matern Fetal Neonatal Med 26: 327-338. [Crossref]

10. De Vivo A, Baviera G, Giordano D, Todarello G, Corrado F, et al. (2008) Endoglin, PlGF and sFlt-1 as markers for predicting pre-eclampsia. Acta Obstet Gynecol Scand 87: 837-842. [Crossref]

11. Garcia-Tizon Larroca S, Tayyar P, Poon LC, Wright D, Nicolaides KH (2014) Competing risks model in screening for preeclampsia to biophysical and biochemical markers at 30-33 weeks' gestation. Fetal Diagn Ther 36: 9-17. [Crossref]

12. Granne I, Southcombe JH, Snider JV, Tannetta DS, Child T, et al. (2011) ST2 and IL33 in pregnancy and pre-eclampsia. PLoS One 6: e24463. [Crossref]

Copyright: (C2017 Basile F. This is an open-access article distributed under the terms of the Creative Commons Attribution License, which permits unrestricted use, distribution, and reproduction in any medium, provided the original author and source are credited. 